\title{
Uso de materiais didáticos instrucionais para inclusão e aprendizagem matemática de alunos cegos
}

Use of instructional materials for inclusion and mathematical learning of blind students

\author{
Ana Paula Poffo Koepsel ${ }^{1}$ \\ Viviane Clotilde da Silva da Silva²
}

\section{Resumo}

O presente artigo discute a importância do uso de materiais didáticos manipuláveis para a inclusão e aprendizagem matemática de alunos cegos. Possui como fundamentação teórica uma discussão sobre inclusão de alunos nas escolas e utilização de materiais didáticos manipuláveis nas aulas de matemática, com o objetivo de uma aprendizagem mais efetiva e uma prática mais inclusiva. Apresenta um dos materiais que constam no produto educacional vinculado a pesquisa que trata deste tema, assim como a análise da sua utilização em uma turma do nono ano do ensino fundamental, onde havia uma aluna cega. Esta pesquisa possibilitou verificar que o uso de materiais didáticos instrucionais nas aulas de matemática com toda turma auxilia na aprendizagem, na inclusão e na interação, não somente do aluno cego, mas de todos.

Palavras-chave: Alunos cegos. Materiais didáticos manipuláveis. Aprendizagem matemática. Inclusão.

\begin{abstract}
This article discusses the importance of the use of manipulative didactic materials for the inclusion and mathematical learning of blind students. It has as theoretical foundation a discussion about the inclusion of students in schools and the use of manipulative didactic materials in mathematics classes, aimed a more effective learning and a more inclusive practice. Presents one of the materials which are in the educational product linked to research about this subject, as well as the analysis of its use in a class of the ninth grade of elementary school with a blind student. This research allowed to verify that the use of instructional didactic materials in math classes with the whole class assists in learning processes, inclusion and interaction, not only for blind student, but for all.
\end{abstract}

\footnotetext{
${ }^{1}$ Mestre em Ensino de Ciências Naturais e Matemática, professora orientadora do Laboratório de Matemática da Escola de Educação Básica Cecília Ax. E-mail: annapaulapoffo@hotmail.com.

${ }^{2}$ Doutora em Educação para Ciência, professora do Departamento de Matemática e do Programa de Pós-Graduação em Ensino de Ciências Naturais e Matemática - PPGECIM, da Universidade Regional de Blumenau-FURB. E-mail: vcs@furb.br.
} 
Key-words: Blind students. Manipulative didactic materials. Mathematical learning. Inclusion.

\section{Introdução}

Apesar de muito se falar em inclusão na sociedade de um modo geral e na inclusão de crianças nas escolas como sendo um direito de todos, a situação em muitas escolas aponta para uma realidade diferente. A prática nos mostra que o que existe é uma exclusão velada, seja dos alunos com problemas de aprendizagem, seja dos alunos com deficiência sensorial, física ou mental, que muitas vezes estão na sala de aula, mas não têm as mesmas oportunidades de aprendizagem.

O Programa de Pós-Graduação em Ensino de Ciências Naturais e Matemática - PPGECIM, da Universidade Regional de Blumenau - FURB, onde esta pesquisa foi desenvolvida, tem entre os seus objetivos construir uma compreensão do processo ensino e aprendizagem, pelas vias do ensino e da pesquisa, que possibilite a formação de professores-pesquisadores de forma que os profissionais ali formados sejam capazes de trabalhar de forma coerente com as estruturas de pensamento exigidas pela ciência e pela tecnologia, relacionando-as com suas inserções na realidade educacional e social ${ }^{3}$.

Diante disso acredita-se que a questão da inclusão de alunos nas aulas de Matemática seja um assunto a ser discutido de forma a buscar caminhos para que todos tenham direito a uma aprendizagem efetiva. Para isto é importante que sejam desenvolvidos estudos nesta área e estes, difundidos entre os professores que atuam nas redes de ensino da Educação Básica. Neste sentido, o Produto Educacional é uma ferramenta que possibilita divulgação das pesquisas desenvolvidas junto aos professores da Educação Básica, uma vez que apresenta, além das atividades desenvolvidas, parte da fundamentação teórica

\footnotetext{
${ }^{3}$ Esta informação consta na página que apresenta o Programa de Pós-Graduação em Ensino de Ciências Naturais e Matemática da Universidade Regional de Blumenau. Disponível em: http://www.furb.br/web/1714/cursos/programa-pos-graduacao/ensino-de-ciencias-naturais-ematematica/apresentacao
} 
que as embasou. Além disso, ele também pode servir de motivador para que estes professores se tornem pesquisadores em suas salas de aula.

Este artigo discute a importância do uso de materiais didáticos manipuláveis para a inclusão e aprendizagem matemática de alunos cegos e é originado de uma dissertação de mestrado defendida em dezembro de 2017. Esta dissertação teve como objetivo principal analisar quais as contribuições da utilização de materiais didáticos manipuláveis na aprendizagem da Matemática de estudantes cegos e o produto educacional desenvolvido a partir desta pesquisa, apresenta os materiais desenvolvidos para o ensino de alunos cegos no $9^{\circ}$ ano do Ensino Fundamental.

Esta pesquisa faz parte de uma pesquisa maior com o título Educação Matemática para Pessoas com Deficiência Visual que tem como objetivo verificar a aprendizagem matemática de alunos com deficiência visual a partir de práticas pedagógicas e materiais específicos ou adaptados para eles, e de um projeto de extensão institucional com o mesmo título que se propõe a produzir e disseminar materiais adaptados para o ensino de matemática de alunos cegos na educação básica, assim como desenvolver cursos divulgando os materiais e as pesquisas desenvolvidas nesta área.

Este trabalho ${ }^{4}$ foi desenvolvido seguindo os parâmetros da pesquisa qualitativa buscando analisar o todo processo de aprendizagem e não simplesmente o resultado apresentado em uma avaliação.

No desenvolvimento deste artigo apresenta-se brevemente a evolução do processo de inclusão no Brasil, o que se entende por inclusão e porque o uso de materiais didáticos manipuláveis é tão importante para a aprendizagem matemática de alunos cegos. Por fim, apresenta-se a metodologia de desenvolvimento da pesquisa e um dos materiais desenvolvidos, assim como as análises da sua aplicação.

\footnotetext{
${ }^{4}$ A presente pesquisa, CAAE número 66723417.5.0000.5370, foi aprovada pelo Comitê de Ética da Universidade Regional de Blumenau/SC com o Parecer número 2.137.273.
} 


\section{Inclusão e aprendizagem matemática de alunos cegos}

A educação de estudantes com deficiência sempre foi motivo para discussão na sociedade. Segundo Mazzotta (2011), no Brasil, já no período imperial, surgiram as primeiras iniciativas para atendimento escolar especial às pessoas com deficiências, mas este processo era sempre de forma assistencialista e sem que houvesse interação entre estes e as pessoas denominadas "normais". Em relação às pessoas cegas, a primeira instituição criada para seu atendimento foi o Imperial Instituto dos Meninos Cegos, que atua hoje sob o nome Instituto Benjamin Constant, no Rio de Janeiro.

Quando se fala em deficiência segue-se o apresentado no art. $3^{\circ}$, inciso I do Decreto oㅜ 3.298, que a define como "[...] toda perda ou anormalidade de uma estrutura ou função psicológica, fisiológica ou anatômica que gere incapacidade para o desempenho de atividade, dentro do padrão considerado normal para o ser humano" (BRASIL, 1999).

Em relação ao ensino das pessoas com deficiência, a Política Nacional de Educação Especial na Perspectiva da Educação Inclusiva (BRASIL, 2008) aponta que, do período imperial até a publicação da Constituição Federal de 1988, elas tinham acesso ao ensino regular, mas não possuíam um atendimento especializado que considerava suas particularidades de aprendizagem. Neste mesmo período também não se efetivou nenhuma "[...] política pública de acesso universal à educação, permanecendo a concepção de 'políticas especiais' para tratar da temática da educação de alunos com deficiência" (BRASIL, 2008, p. 07).

De acordo com Silveira (2010, p. 20), nas décadas de 1970 e 1980 "[...] surge o termo integração, oferecendo estudo aos alunos com necessidades educacionais especiais junto aos demais alunos", ou seja, os estudantes com deficiência poderiam estudar, mas teriam que se adaptar ao ensino que a escola oferecia.

Deste modo, nesse período, as pessoas com deficiência eram integradas nas turmas de ensino regular, mas não incluídas, ou seja, o objetivo da integração 
no ensino regular era "[...] 'normalizar' o indivíduo, a nível físico, funcional e social, pressupondo a proximidade física, a interacção, a assimilação e a aceitação" (SILVA, 2009, p. 141). Silva (2009) ainda destaca que, muitas vezes, no processo de integração os estudantes com deficiência não eram inseridos nas salas de aula regulares, uma vez que se acreditava que eles perturbariam a turma, sendo atendidos em salas separadas, próprias para eles. Por meio desta integração os estudantes com deficiência deveriam se adaptar as exigências da escola e não a escola mudar para recebê-los. A ideia de integração é oposta da defendida no processo de inclusão, onde não é o estudante com deficiência que deve se adaptar a escola, mas o contrário, a escola deve estar preparada para trabalhar com todos em suas salas de aula regulares sendo que, quando necessário, haja auxílio de educação especial.

Segundo Passos (2014), somente na década de 1990, a partir da Declaração de Salamanca (1994) assinada por representantes de vários países (inclusive do Brasil), a inclusão dos estudantes com deficiência no ensino regular começa a ter força. Neste documento consta que "[...] toda criança tem direito fundamental à educação, e deve ser dada a oportunidade de atingir e manter o nível adequado de aprendizagem". Atualmente há, na legislação brasileira, várias leis (Brasil 1988, 1994, 1996, 1999, 2001, 2002, 2004, 2005, 2006, 2008, 2015) que garantem a inclusão das pessoas com deficiência não apenas na educação, mas também na sociedade de um modo geral.

Todo este processo fez com que se alterasse a ideia de como deve ser o trabalho com os alunos com deficiência nas escolas, hoje se tem a Lei Brasileira de Inclusão da Pessoa com Deficiência - Lei 13.146/15, que no capítulo IV, art. 28, inciso II desta lei, garante o "aprimoramento dos sistemas educacionais, visando a garantir condições de acesso, permanência, participação e aprendizagem, por meio da oferta de serviços e de recursos de acessibilidade que eliminem as barreiras e promovam a inclusão plena" (BRASIL, 2015). Neste artigo, quando se fala em inclusão é nisto que se está referindo, a condições de acesso, permanência, participação e aprendizagem de todos. 
As leis são bem claras em relação à inclusão e ao ensino dos estudantes com deficiências, mas para que a inclusão realmente aconteça nas escolas necessita-se, além de leis que garantam a educação, escolas e pessoas preparadas para recebê-los. É essencial que os professores possuam uma formação apropriada que os permita realizar adequações necessárias na sua forma de lecionar para cada tipo de necessidade dos estudantes.

Em pesquisa realizada com professores de matemática de Santa Catarina questionando-os sobre sua formação em relação ao ensino de alunos com deficiência a maioria respondeu que na sua formação não teve disciplinas que abordassem aspectos do ensino destes alunos.

As dificuldades acerca do ensino e da inclusão de estudantes com deficiências foram a motivação para se desenvolver uma pesquisa sobre este assunto. O ensino de Matemática para cegos foi escolhido, pois esta é um componente curricular que trabalha com objetos abstratos, necessitando para sua melhor compreensão de representações, que muitas vezes são exploradas pelos professores de forma visual, o que dificulta a compreensão da mesma pelo estudante cego, que fica alheio ao que acontece na sala de aula.

Apesar de restringir a relação da pessoa com o mundo, a deficiência visual não deve ser entendida como uma incapacidade ou limitação, pois a pessoa cega possui a mesma potencialidade do indivíduo com visão normal.

Segundo Vygotski (1997, p. 99, tradução nossa), a cegueira "não é somente um defeito, uma deficiência, uma fraqueza, mas também, em certo sentido, uma fonte de revelações de habilidades, uma vantagem, uma força". O mesmo autor salienta que, quando um indivíduo nasce sem, ou perde, uma das funções da percepção ou um órgão, a falta deste se compensa com o desenvolvimento dos outros órgãos ou sentidos. Para ele a deficiência, ao invés de ser uma fraqueza ou uma carência psíquica é energia e riqueza, pois é através da sua compensação que o indivíduo se desenvolve.

Diante disso, para proporcionar um ensino de qualidade, é preciso possibilitar aos estudantes a utilização de todos os sentidos (e não apenas a 
visão) para captar as informações, fornecendo assim um ensino adequado às necessidades dos mesmos. No caso da falta de um dos sentidos, o estudante poderá utilizar os remanescentes que, segundo Sá, Campos e Silva (2007, p. 21) "[...] são importantes canais ou porta de entrada de dados e informações que serão levados ao cérebro." No caso dos estudantes com deficiência visual, acredita-se que uma maneira de privilegiar os outros sentidos é a utilização de materiais didáticos manipuláveis.

De acordo com Lorenzato (2006) os materiais didáticos são definidos como qualquer ferramenta que seja útil ao processo de ensino e aprendizagem, alguns exemplos de materiais são os jogos, a calculadora, o caderno, o computador, etc. O mesmo autor salienta que os materiais didáticos são recursos importantes no processo de ensino e aprendizagem e são de fácil utilização, podendo executar funções diferentes, como motivar os estudantes, introduzir um assunto, auxiliar no entendimento e facilitar a redescoberta, dependendo do objetivo da aula.

O ensino de Matemática para as pessoas com deficiência visual, é um desafio para o professor, pois, como já foi dito, neste componente curricular muitas vezes a visualização é um dos principais instrumentos utilizados para o entendimento de determinados conteúdos, o que acaba dificultando a aprendizagem destes estudantes. Para que o estudante com deficiência visual consiga entender os conteúdos que normalmente são abordados de forma visual, é necessário que o professor deixe aflorar sua criatividade e busque meios distintos de trabalhá-los, meios que possibilitem a aprendizagem destes estudantes. Arruda (2014) destaca que a expressão criativa no trabalho pedagógico não significa somente inserir novidades ou fazer diferente em sua prática educativa, mas sim fazer algo que ofereça oportunidade de aprendizagem a todos estudantes.

Segundo Gil (2000) para que o estudante com deficiência visual tenha as mesmas condições de aprender Matemática que o vidente, é essencial que se utilize materiais didáticos e representações gráficas adaptadas, contribuindo assim não apenas para a aprendizagem do estudante com deficiência visual, mas 
também para todos os estudantes da turma. Este processo auxilia tanto na aprendizagem quanto na inclusão do estudante com deficiência visual nas aulas, pois desta forma o estudante cego tem a possibilidade de interagir e discutir com seus colegas sobre o que está sendo estudado, além de que os materiais projetados inicialmente para o estudante cego podem também auxiliar um vidente que tenha dificuldade de aprendizagem.

Em conformidade, Rosa (2017, p. 222) destaca que a elaboração "[...] de objetos matemáticos táteis visa uma aprendizagem significativa sem excluir os alunos que têm dificuldade de visualizar, mesmo quando o professor desenha no quadro". A mesma autora completa dizendo que o professor deve utilizar mais os outros sentidos dos estudantes e enfocar menos na visão.

O estudante com deficiência visual possui as mesmas possibilidades de aprendizagem que um estudante vidente, as dificuldades no processo de aprendizagem da Matemática não são cognitivas, mas de ordem técnica e material e acabam condicionando o ritmo de trabalho em que o estudante aprende este componente curricular (FERNANDES; HEALY, 2007).

Outro ponto importante a ser destacado é o uso das dêixis nas aulas de Matemática. De acordo com Lavarda e Bidarra (2007, p. 309) dêixis são expressões "de referenciação linguística que tem por função relacionar, no ato, de enunciação certas unidades gramaticais às coordenadas espaço-temporais." $\mathrm{E}$, segundo Miranda (2016, p. 131), em uma aula expositiva a dêixis é utilizada ao extremo, pois muitas vezes o professor faz referência ao que está explicando apontando para uma representação escrita ou desenhada, sem descrevê-la, gerando assim dificuldades de compreensão para o aluno que não enxerga. Logo, quando se tem um estudante com deficiência visual em sala e o professor fizer o uso do quadro negro ou de algum material didático para explicar algum conteúdo, ele deve sempre descrever o que está apresentando para que este estudante possa acompanhar a explicação. 


\section{A importância do uso de materiais didáticos manipuláveis nas aulas de matemática para estudantes cegos}

O ensino tradicional, principalmente no que se refere ao componente curricular Matemática, baseado na exposição teórica do conteúdo, não satisfaz as necessidades dos estudantes que muitas vezes não conseguem entender os conceitos explorados. Esta dificuldade se torna ainda maior para estudantes com deficiência que necessitam de formas alternativas de ensino para auxiliar na aprendizagem, conforme apontam as autoras Shimazaki, Silva e Viginheski (2016, p. 150):

O ensino de Matemática, fundamentado na prática pedagógica tradicional, que reduz o ensino da disciplina à apresentação de conceitos já elaborados, ao uso do livro didático, do quadro e do giz, pode ser considerado como uma prática pedagógica excludente, uma vez que não atende à diversidade, pois não proporciona aos estudantes, especialmente aos estudantes com deficiências, diferentes caminhos e possibilidades para a elaboração do conhecimento científico, conforme suas necessidades.

Para que os estudantes compreendam o conteúdo matemático abordado em sala de aula é necessário que tenha uma relação mediadora, visto que esta é uma ciência que trabalha com objetos ideais e não reais. Segundo Silva (2015) normalmente esta relação é feita através do uso de linguagem visual e oral, não favorecendo a todos os estudantes, principalmente o cego que muitas vezes não tem possibilidade de imaginar o que está sendo explicado apenas por expressões descritas. Desta forma, a mesma autora ainda destaca para que todos tenham a mesma possibilidade de aprendizado torna-se fundamental utilizar instrumentos mediadores que atendam às necessidades de cada estudante.

Para os estudantes com deficiência visual compreenderem algum conteúdo, eles necessitam coletar as informações por meio dos outros sentidos tato, audição, paladar e olfato, sendo o tato o mais utilizado. Reily (2004) salienta que garantindo o acesso ao conteúdo pelos sentidos restantes e disponibilizando 
o tempo que for necessário, estes estudantes terão condições de aprendizagem equivalentes aos videntes.

Neste sentido, o uso de materiais didáticos manipuláveis na sala de aula que possui um estudante com deficiência visual visa proporcionar a utilização dos sentidos remanescentes, principalmente 0 tato, possibilitando a sua aprendizagem. Por este motivo, Sá, Campos e Silva (2007) ressaltam que é necessária a utilização pelos professores de outros materiais em sala de aula, não somente aqueles de estímulos visuais, mas também os que envolvam a exploração por meio dos outros sentidos.

Em conformidade, destaca-se que para um estudante cego "[...] é muito difícil fazer a representação visual de um desenho, logo, o material manipulável pode permitir que se representem certos assuntos da matemática por outras vias" (SILVA, 2015, p. 49). A afirmação da autora reforça que durante as aulas de Matemática é necessário proporcionar aos estudantes cegos a utilização dos sentidos remanescentes para coletar informações.

Para os estudantes com deficiência visual a utilização de texturas, tamanhos e formas diferenciadas nos materiais didáticos manipuláveis é essencial, pois é através destes que a elaboração e a construção do conceito matemático serão feitas por estes estudantes. Kaleff e Rosa (2016, p. 32) afirmam que ao manusear um material concreto que representa um conceito matemático, "[...] o aluno com deficiência visual, manipula (enxerga com as mãos) esse conceito modelado e obtém uma imagem mental advinda da percepção tátil". Ou seja, a manipulação do material possibilitará o entendimento de forma mais fácil, pois para as pessoas com esta deficiência a imagem visual é resultante da percepção tátil (KALEFF e ROSA, 2016).

Diante destas colocações é possível perceber que para os estudantes com deficiência visual terem um ensino de Matemática inclusivo, que os possibilitem a participação ativa durante a aula e a aprendizagem, é necessário que o professor planeje sua prática de uma forma diferenciada e que sejam utilizados materiais didáticos manipuláveis adaptados. A importância dos materiais se dá no fato de 
que o uso destes contribui em vários fatores como proporcionar a utilização dos sentidos remanescentes, estimular a percepção tátil, possibilitar o acesso ao conhecimento e a construção de conceitos matemáticos, auxiliando no ensino e aprendizagem destes estudantes.

\section{Metodologia de desenvolvimento da pesquisa}

Inicialmente realizou-se uma pesquisa referente aos documentos que fundamentam a inclusão de alunos com deficiência, sobre o ensino e a aprendizagem de alunos cegos e pesquisas desenvolvidas sobre estes temas. Para o desenvolvimento dos materiais houve a colaboração de uma professora que atuava no nono ano do ensino fundamental de uma escola pública e possuía uma aluna cega. Esta professora apresentou os conteúdos que seriam explorados para que fossem desenvolvidos materiais para auxiliar os alunos no seu entendimento. Estes materiais foram estudados, confeccionados e testados para, na sequência, serem aplicados pela professora colaboradora em suas aulas e então analisados primeiramente por ela e pela aluna cega.

Com base no apresentado pela professora e na teoria que fundamenta esta pesquisa foi realizada uma análise final de cada material confeccionado buscando verificar se eles realmente auxiliavam na aprendizagem matemática, se o uso destes materiais durante as aulas, possibilitando que os outros alunos também tivessem acesso ao mesmo, contribuíam para a inclusão e interação da aluna cega com toda turma e participação da mesma durante as aulas.

Ao final desta pesquisa foi desenvolvido como produto educacional um caderno direcionado ao professor com instrução de como confeccionar os materiais desenvolvidos e sugestões de uso dos mesmos com base na experiência realizada, para que outro professor interessado possa também utilizar esta pesquisa em sua prática e, com base na mesma, produzir outros materiais de seu interesse. 


\section{Exemplo de material desenvolvido e análise}

A presente pesquisa foi realizada em uma escola de ensino fundamental pública, junto a uma professora de Matemática que possui uma estudante cega. A turma na qual foram aplicados os materiais desenvolvidos é uma turma de $9^{\circ}$ ano do Ensino Fundamental, com 26 estudantes. A estudante cega que utilizou os materiais tinha 14 anos (em 2017) e nasceu com retinopatia da prematuridade, de modo que é cega congênita, não possuindo nenhuma memória visual. A escolha ocorreu devido ao interesse da professora colaboradora em aplicar os materiais didáticos manipuláveis com sua estudante e participar da pesquisa.

Na sequência será apresentado um dos materiais desenvolvidos e a análise do mesmo. Importante ressaltar que muitos dos materiais desenvolvidos são bastante simples e até mesmo apresentados nos livros didáticos, apenas com algumas adaptações para que possam ser utilizados por alunos cegos. O objetivo é conscientizar os professores da importância do uso de materiais para auxiliar na compreensão dos conceitos matemáticos, mostrando que eles podem ser simples e de fácil confecção, muitas vezes até pelos próprios alunos.

Este material tem o objetivo de representar geometricamente e levar os alunos a compreenderem o Teorema de Pitágoras por meio de cálculo de área, e para isso foi desenvolvida uma representação utilizando EVA (liso e com textura para aluna cega), papel cartão e barbante.

Em um painel (papel cartão) foi desenhado um triângulo retângulo e três quadrados a partir dos lados deste triângulo. No triângulo a hipotenusa deve medir cinco unidades e os catetos, quatro e três unidades, respectivamente. Os contornos do triângulo e dos quadrados devem ser feitos com o barbante para o aluno cego ter noção dos limites das figuras. No caso do material desenvolvido para a aluna cega cada unidade foi feita com a medida de $4 \mathrm{~cm}$ e dos alunos videntes cada unidade media $1 \mathrm{~cm}$. Recortar dezesseis quadrados de lado medindo 1 unidade feitos de EVA com textura e nove de EVA sem textura (para 
os alunos videntes utiliza-se somente EVA sem textura, de cores diferentes), conforme a Figura 1.

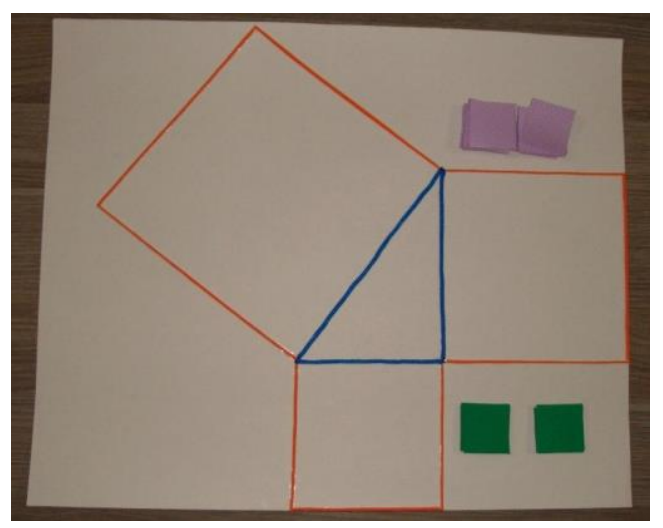

Figura 1: Modelo para representação geométrica do Teorema de Pitágoras Fonte: acervo do autor (2017)

Este material serve para mostrar o Teorema de Pitágoras por meio da equivalência de áreas, ou seja, a área do quadrado cujo lado equivale a medida da hipotenusa é equivalente a soma das áreas dos dois quadrados cujos lados equivalem a medida dos catetos do triângulo retângulo, como apresentado na Figura 2.
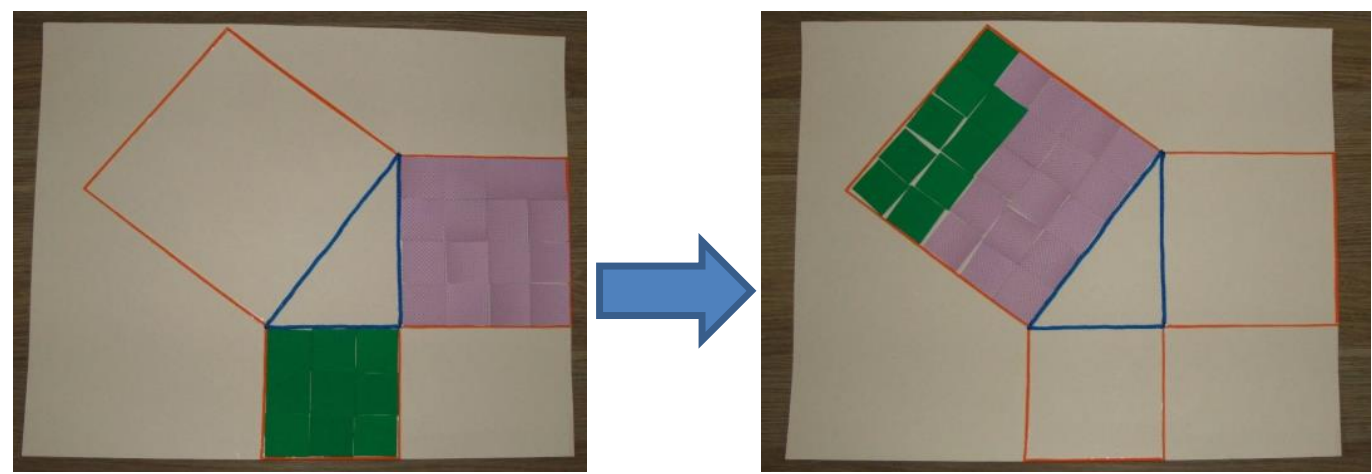

Figura 2: Representação geométrica do Teorema de Pitágoras Fonte: acervo do autor (2017)

A professora achou o material interessante e para o desenvolvimento desta aula preferiu não utilizar o material construído e disponibilizado, mas solicitou que os estudantes construíssem seu próprio material (com os quadrados tomados 
como unidades um pouco maiores) e fizessem a verificação. A estudante cega construiu seu material com auxílio de uma colega, conseguindo também verificar a equivalência. Esta prática reforça a afirmação de Silva (2015) de que possibilitar que o estudante cego construa seu próprio material com auxílio dos outros estudantes contribui para que haja interação entre eles.

Em relação a inclusão, de acordo com o depoimento da professora, ao utilizar o material a estudante participou de toda a atividade interagindo com os colegas de turma, isso aconteceu pelo fato de que foram dadas as mesmas oportunidades de aprendizagem aos estudantes, conforme Fernandes (2008) que afirma que não se deve pensar somente na desvantagem do estudante com deficiência, mas em proporcionar oportunidades iguais para o desenvolvimento e aprendizagem de todos estudantes.

Segundo a professora, os estudantes participaram da atividade com entusiasmo e acharam-na desafiadora. Este depoimento deixou clara a importância da utilização dos materiais didáticos nas aulas de Matemática, servindo de mediadores concretos para o entendimento do conceito explorado. Silva (2015) destaca que estes materiais muitas vezes são de grande auxílio, pois exercem "[...] função mediadora, não só ao aluno cego, mas a todos os alunos" (p. 159).

Sobre a aprendizagem, a professora relatou que o material auxiliou na compreensão do conteúdo abordado de forma geométrica pela estudante cumprindo sua função de "[...] ser auxiliar para a abstração matemática, ou seja, proporcionar ajuda para fundamentar e facilitar um caminho ao raciocínio abstrato lógico-dedutivo" (KALEFF, 2016, p. 59).

\section{Considerações finais}

Neste artigo buscou-se apresentar um pouco da pesquisa desenvolvida com objetivo de "analisar quais as contribuições dos materiais didáticos manipuláveis na aprendizagem da Matemática de estudantes cegos", 
desenvolvida junto a uma professora do $9^{\circ}$ Ano do Ensino Fundamental de uma escola pública do município de Blumenau/SC, que possui uma estudante cega. Nele também se apresentou um dos materiais desenvolvidos e que constam no produto educacional desta dissertação, assim como a análise da utilização do mesmo.

Esta pesquisa mostrou que os materiais desenvolvidos auxiliaram não apenas para a compreensão do conteúdo pela estudante cega, mas também na relação dela com seus colegas de turma. A professora relatou que a estudante não quer trabalhar com materiais adaptados desenvolvidos somente para ela, pois não quer se sentir diferente, mas quando todos desenvolveram o material da mesma forma e trabalharam junto ela aceitou. Deste modo, pode-se perceber que os materiais além de auxiliarem na aprendizagem da estudante cega e dos estudantes videntes também contribuíram para a inclusão desta na turma.

Durante o percurso desta pesquisa surgiram algumas dificuldades. Algumas técnicas como: a demora da prefeitura de Blumenau/SC na autorização para o desenvolvimento da pesquisa e em fornecer os nomes das escolas onde possuíam estudantes com deficiência visual; e a demora em se obter a aprovação do projeto de pesquisa pelo comitê de ética. Outra diz respeito a dificuldade da estudante cega em resolver cálculos algébricos (que não foram devidamente explorados e desenvolvidos nos anos anteriores, segundo sua professora), isso acabou dificultando a utilização de alguns dos materiais propostos, que exigiam um raciocínio mais abstrato. Como sugestão para trabalhos futuros propõe-se a elaboração de materiais didáticos e/ou atividades para estudantes cegos, que auxiliem no desenvolvimento do raciocínio algébrico para ser trabalhado nos anos anteriores ou paralelamente, para auxiliar o estudante cego com esta defasagem.

Acredita-se que esta pesquisa e o produto educacional desenvolvido a partir da mesma, e que está sendo disseminado aos professores da região, venham auxiliar não somente aqueles que têm alunos cegos, mas também aqueles que têm alunos com dificuldades de aprendizagem, pois ele apresenta 
outras formas de levar o aluno a buscar compreensão dos conceitos matemáticos, com sugestões de como utilizar os materiais desenvolvidos.

\section{Referências}

ARRUDA, Tatiana Santos. A criatividade no trabalho pedagógico do professor e o movimento em sua subjetividade. 2014. $269 \mathrm{f}$. Tese (Doutorado) - Programa de PósGraduação em Educação, Faculdade de Educação, Universidade de Brasília, Brasília, 2014. Disponível em: <http://repositorio.unb.br/handle/10482/17574>. Acesso em: 05 out. 2017.

BRASIL. Casa Civil. Constituição da República Federativa do Brasil de 1988. Brasília, 1988. Disponível em:

$<$ http://www.planalto.gov.br/ccivil 03/constituicao/constituicaocompilado.htm $>$. Acesso em: 07 set. 2016.

Declaração de Salamanca. Conferência mundial sobre necessidades educativas especiais: acesso e qualidade, Espanha, 1994. Disponível em: $<$ http://portal.mec.gov.br/seesp/arquivos/pdf/salamanca.pdf $>$. Acesso em: 07 set. 2016.

Casa Civil. Decreto 3.298, de 20 de dezembro de 1999. Brasília, 1999. Disponível em: <http://www.planalto.gov.br/ccivil 03/decreto/d3298.htm>. Acesso em: 01 fev. 2017.

Parecer $n^{\circ}$ 17, de 03 de janeiro de 2001. Diretrizes Nacionais para a Educação Especial na Educação Básica. Brasília, 2001a. Disponível em: $<$ http://portal.mec.gov.br/cne/arquivos/pdf/CEB017 2001.pdff. Acesso em: 23 fev. 2017.

Casa Civil. Lei no 10.436, de 24 de abril de 2002. Dispõe sobre a Língua Brasileira de Sinais - Libras e dá outras providências. Brasília, 2002. Disponível em: $<$ http://www.planalto.gov.br/ccivil 03/LEIS/2002/L10436.htm>. Acesso em: 01 fev. 2017. BRASIL. Casa Civil. Decreto 5.296, de 02 de dezembro de 2004. Brasília, 2004. Disponível em: <http://www.planalto.gov.br/ccivil 03/ ato20042006/2004/decreto/d5296.htm>. Acesso em: 20 ago. 2016.

Casa Civil. Decreto 5.626, de 22 de dezembro de 2005. Brasília, 2005.

Disponível em: <http://www.planalto.gov.br/ccivil 03/ ato20042006/2005/decreto/d5626.htm>. Acesso em: 01 fev. 2017.

Ministério da Educação. Secretaria de Educação Especial. Saberes e práticas da inclusão: desenvolvendo competências para o atendimento às necessidades especiais de alunos cegos e de alunos com baixa visão. 2. ed. Brasília: MEC, 2006. 208 p. 
Ministério da Educação. Política Nacional de Educação Especial na

Perspectiva da Educação Inclusiva. Brasília, 2008. Disponível em:

http://portal.mec.gov.br/arquivos/pdf/politicaeducespecial.pdf>. Acesso em: 15. nov. 2016.

Casa Civil. Lei 13.146, de 6 de julho de 2015. Lei Brasileira de Inclusão da Pessoa com Deficiência. Brasília, 2015. Disponível em: < http://www.planalto.gov.br/ccivil 03/ Ato2015-2018/2015/Lei/L13146.htm>. Acesso em: 07 set. 2016.

FERNANDES, Solange Hassan Ahmad Ali; HEALY, Lulu. Ensaio sobre a inclusão na Educação Matemática. UNIÓN: Revista Iberoamericana de Educación Matemática, San Cristobal de La Laguna, n. 10, p. 59-76, jun. 2007. Disponível em: <http://www.fisem.org/www/union/revistas/2007/10/Union 010 010.pdf>. Acesso em: 06 fev. 2017.

FERNANDES, Solange Hassan Ahmad Ali. Das experiências sensoriais aos conhecimentos matemáticos: uma análise das práticas associadas ao ensino e aprendizagem de alunos cegos e com visão subnormal numa escola inclusiva. 2008. 274 f. Tese (Doutorado) - Programa de Pós-Graduação em Educação Matemática, Pontifícia Universidade Católica de São Paulo, São Paulo, 2008. Disponível em: <https://tede2.pucsp.br/handle/handle/11344>. Acesso em: 11 jan. 2017.

GIL, Antonio Carlos. Como elaborar projetos de pesquisa. 5.ed. São Paulo: Atlas, 2010. 200 p.

KALEFF, Ana Maria Martensen Roland. Aprendizagem significativa criativa em ambiente de laboratório de ensino. In: KALEFF, Ana Maria Martensen Roland. (Org.). Vendo com as mãos, olhos e mente: Recursos didáticos para laboratório e museu de educação matemática inclusiva do aluno com deficiência visual. Niterói: CEAD / UFF, 2016, p. 5262.

KALEFF, Ana Maria Martensen Roland; ROSA, Fernanda Malinosky Coelho da. A importância da habilidade da visualização para a aprendizagem matemática e para a inclusão do aluno com deficiência visual. In: KALEFF, Ana Maria Martensen Roland. (Org.). Vendo com as mãos, olhos e mente: Recursos didáticos para laboratório e museu de educação matemática inclusiva do aluno com deficiência visual. Niterói: CEAD / UFF, 2016, p. 28-36.

LAVARDA, Santa Terezinha Falcade; BIDARRA, Jorge. A dêixis como um "complicador/facilitador" no contexto cognitivo e linguístico em ambiente educacional face aos alunos com deficiência visual. Revista Brasileira de Educação Especial, Marília, v.13, n.3, p. 309-324, Set.-Dez, 2007. Disponível em: <http://www.scielo.br/pdf/rbee/v13n3/a02v13n3.pdf >. Acesso em: 10 jan. 2018.

LORENZATO, Sergio. Laboratório de ensino de matemática e materiais didáticos manipuláveis. In: LORENZATO, Sergio (Org.). Laboratório de Ensino de Matemática na formação de professores. Campinas: Autores Associados, 2006, p. 3-38. 
MAZZOTTA, Marcos José Silveira. Educação Especial no Brasil: história e políticas públicas. 6. ed. São Paulo: Cortez, 2011. 232 p.

MIRANDA, Edinéia Terezinha de Jesus. $O$ aluno cego no contexto da inclusão escolar: desafios no processo de ensino e de aprendizagem de matemática. 2016. 167 f. Dissertação (Mestrado) - Programa de Pós Graduação em Educação para a Ciência, Universidade Estadual Paulista, Bauru, 2016. Disponível em:

<http://hdl.handle.net/11449/139502>. Acesso em: 10 jan. 2018.

PASSOS, Angela Meneghello. Uma proposta para a análise das relações docente em sala de aula com perspectivas de ser inclusiva. 2014. $131 \mathrm{f}$. Tese (Doutorado) Ensino de Ciências e Educação Matemática, Universidade Estadual de Londrina, Londrina, 2014. Disponível em:

$<$ http://www.bibliotecadigital.uel.br/document/?view=vtls000189853 >. Acesso em: $13 \mathrm{dez}$. 2016.

AUTOR, Plano Plurianual do Programa de Pós-Graduação ..., 2016 (Documento digitado)

REILY, Lúcia. Escola inclusiva: Linguagem e mediação. Campinas: PAPIRUS, 2004. $192 \mathrm{p}$.

ROSA, Fernanda Malinosky Coelho da; BARALDI, Ivete Maria. Narrativas de Si: o que professores (de matemática) e alunos com deficiência visual contam sobre suas formações? Revista Paranaense de Educação Matemática - RPEM, Campo Mourão, v. 6, n. 10, p. 118-134, jan./jun. 2017. Disponível em: <http://www.fecilcam.br/revista/index.php/rpem/article/view/1221>. Acesso em: 20 out. 2017.

SÁ, Elizabet Dias de; CAMPOS, Izilda Maria de; SILVA, Myriam Beatriz Campolina. Atendimento Educacional Especializado: Deficiência Visual. Brasília: Cromos, 2007. $57 \mathrm{p}$.

SHIMAZAKI, Elsa Midori; SILVA, Sani Carvalho Rutz da; VIGINHESKI, Lúcia Virginia Mamcasz. O ensino de Matemática e a diversidade: o caso de uma estudante com deficiência visual. Interfaces da Educação, Paranaíba, v. 6, n. 18, p.148-164, set./dez. 2016. Disponível em:

$<$ http://periodicosonline.uems.br/index.php/interfaces/article/view/1082/913>. Acesso em: 21 nov. 2016.

SILVA, Maria Odete Emygdio da. Da Exclusão à Inclusão: Concepções e Práticas. Revista Lusófona de Educação, Lisboa, n. 13, p. 135-153, jun. 2009. Disponível em: $<$ http://www.scielo.mec.pt/scielo.php?script=sci arttext\&pid=S164572502009000100009 >. Acesso em: 24 fev. 2017.

SILVA, Lessandra Marcelly Sousa da. Do improviso às possibilidades de ensino: estudo de caso de uma professora de Matemática no contexto da inclusão de estudantes cegos. 2015. 194f. Tese (Doutorado) - Programa de Pós-Graduação em Educação Matemática, Universidade Estadual Paulista "Júlio de Mesquita Filho", Rio Claro, 2015. 
http://dx.doi.org/10.5965/2357724X06112018413

Disponível em: <https://repositorio.unesp.br/handle/11449/136763>. Acesso em: 21 nov. 2016.

SILVEIRA, Cíntia Murussi. Professores de alunos com deficiência visual: saberes, competências e capacitação. 2010. 135 f. Dissertação (Mestrado) - Mestrado em Educação, Pontifícia Universidade Católica do Rio Grande do Sul, Porto Alegre, 2010. Disponível em: <http://tede2.pucrs.br/tede2/bitstream/tede/3629/1/421421.pdf > . Acesso em: 13 dez. 2016.

VYGOTSKI, Lev Semiónovic. Obras Escogidas V: Fundamentos de Defectología. Madrid: Visor, 1997. 391 p. 